\title{
SPATIAL RESOLUTION ESTIMATION OF CBERS-1 AND CBERS-2 CCD CAMERAS
}

\author{
K. BENSEBAA ${ }^{1}$, G. J. F. BANON ${ }^{2}$, L. M. G. FONSECA ${ }^{2}$ \\ ${ }^{1}$ Computer Sciences Department - Federal University of Sergipe \\ Avenida Marechal Rondon, $\mathrm{s} / \mathrm{n}$ \\ Cidade Universitária Professor José Aloísio de Campos - São Cristovão \\ SE - Brazil \\ ${ }^{2}$ Image Processing Division - National Institute for Space Research (INPE) \\ Av. dos Astronautas, 1758, 12201-027 São José dos Campos \\ SP- Brazil
}

\begin{abstract}
MTF (Modulation Transfer Function) is a means of characterizing sensor spatial resolution and is used to measure image quality during in-flight commissioning phase. Another important parameter is the Effective Instantaneous Field of View (EIFOV), which is also used to measure system performance. This work describes three approaches to estimate the effective spatial resolution of CCD cameras aboard CBERS-1 and CBERS-2. These approaches use artificial and natural targets to estimate the EIFOV in across-track and along-track directions. CBERS-1 and CBERS-2 have the same specifications and carry three sensors: Wide Field Imager (WFI), High Resolution Charge Coupled Device (CCD) Camera, and Infrared Multispectral Scanner (IRMSS). The results obtained from these methods are compared with those of pre-flight measurements. The results have shown that the effective spatial resolutions in the across-track direction, for both CBERS-1 and CBERS-2 cameras, are worse than those in the along-track direction. Besides, it has been observed that their spatial resolutions are not consistent with the camera specifications in both directions. Although the methodologies presented here have been used to estimate the spatial resolution of CCD cameras aboard CBERS satellite, they can also be used to estimate the spatial resolution of similar sensors.
\end{abstract}

Keywords: CCD Camera, Spatial Resolution, Modulation Transfer Function, target simulation, Point Spread Function, EIFOV.

\section{Introduction}

In the last two decades China and Brazil have jointly developed CBERS satellites (China-Brazil Earth Resources Satellite). CBERS-1 and CBERS-2 satellites were launched on 14 October 1999 and on 21 October 2003, respectively, by the Chinese launcher Long-March 4B, from the Tayuan Launch Center, in 
the People's Republic of China. They carry three instruments: CCD (Charge Coupled Device) camera, IRMSS (Infrared MSS) and WFI (Wide Field Imager), which capture optical images of the Earth surface and transmit them to ground stations.

The cumulative effects of the optical and electronic systems (diffraction, aberrations, focusing error, noise) and the the relative motion between the scene and the camera induced by the movement of the satellite degrade the camera spatial resolution (Leger et al. 2002). Hence, the images may have a blurred appearance which is likely to compromise their visual quality and analysis tasks.

One way to evaluate the blurring effect of a sensor is through its effective spatial resolution, which can be determined in terms of the Point Spread Function (PSF) or Modulation Transfer Function (MTF) of the sensor. The imaging system MTF (or PSF) is of fundamental importance in both the initial specification and design of the system and in the subsequent detailed analysis of the images it produces. Basically, there are three approaches to determine the PSF or MTF of an imaging system. They are based on experimental methods or on theoretical modelling of the physical processes under study. The first one uses artificial or natural targets with well-defined shape and size such as airport runways, bridges, edges, etc. The second approach consists of adjusting the parameters of a simulated low-resolution image in order to match an image of the same scene acquired by the sensor under study. According to Storey (2001), this method works satisfactorily if the two sets of imagery are acquired at or around the same time or, at least, under similar conditions to avoid temporal variations related problem. The third approach uses the imaging system specifications to model its spatial response. Storey (2001) provided a methodology for on-orbit spatial resolution estimation of Landsat-7 ETM + sensor, in across-track direction, by using a Causeway bridge image (Louisiana - USA). Choi and Helder (2003) used an airport runway and a tarp placed on the ground for on-orbit MTF measurement of IKONOS satellite sensor. Other works (Nelson and Barry, 2001; Leger et al., 2002; Luxen and Forstner, 2002) also used similar approaches to estimate the system PSF. Fonseca and Mascarenhas (1987) and Markham (1985) used a method based on the sensor MTF model to estimate the effective spatial resolution of the TM and MSS sensors (Landsat-5 satellite). 
Differently from previous papers, in this work we present a complete framework, consisting of three methods, to evaluate the spatial resolution of orbital sensors, in both along and across-track directions, assuming that the necessary information about targets or high resolution images are available. The methods described here, are tested in three experiments for the evaluation of CCD cameras aboard CBERS-1 and CBERS-2 spatial response.

The first experiment in this paper uses an image of a black squared target set up in the Gobi desert (China). The CCD spatial response is modelled as 2D Gaussian function, which is characterized by two parameters: one in along-track direction and the other in across-track direction. The EIFOV values are then derived from these parameters (Bensebaa et al., 2004a). The second experiment models the imaging system point spread function by a separable Gaussian function in the across- and along-track directions. Images of natural targets such as the Rio-Niterói Bridge over Guanabara Bay (Brasil) and Causeway bridge over the Lake Pontchartrain (United States) are used to estimate the spatial resolution in the along-and across-track directions, respectively (Bensebaa et al., 2004b). The third experiment determines the spatial resolution of CBERS-CCD cameras using a higher spatial resolution image acquired by SPOT-4 satellite and an image of the same scene acquired by CBERS satellite (Bensebaa et al., 2005).

This paper is organized in the following way. Section 2 gives a brief overview of CBERS-CCD camera. Section 3 introduces a theoretical basis of spatial resolution and the relation between the MTF or PSF and the EIFOV parameter. Section 4 describes the first approach to estimate on-orbit CBERS CCD spatial resolution using images of an artificial black squared target in the Gobi desert (China). Section 5 introduces a second approach using two natural targets: an image of the Rio-Niterói bridge, over Guanabara bay (Rio de Janeiro - Brazil), and an image of the Causeway bridge over Pontchartrain lake (Louisiana - USA). Section 6 presents the last approach which uses an image of higher spatial resolution (SPOT-4) than that of a CBERS-CCD. Section 7 discusses and analyses the results obtained from the three proposed methodologies to estimate CBERS-1 and CBERS-2 CCD camera spatial resolution. Finally, Section 8 presents the conclusions. 


\section{CBERS CCD camera}

CBERS-1 and CBERS-2 CCD cameras have 4 spectral bands from visible to near infrared spectrum and one panchromatic band (Table. 1). These CCD cameras acquire Earth ground scenes by pushbroom scanning while on $778 \mathrm{~km}$ sun-synchronous orbit and provide images of $113 \mathrm{~km}$ wide strips with sampling rate of 20 meters at nadir. Since these cameras have a sideways pointing capability of \pm 32 degrees, they are capable of capturing stereoscopic images of a certain region.

The signal acquisition system operates in two channels called CCD1 and CCD2. The first one generates images corresponding to Bands B2, B3 and B4 while the second generates images corresponding to Bands $\mathrm{B} 1, \mathrm{~B} 3$ and B5. In each channel (channel $\mathrm{C} 1$ and channel $\mathrm{C} 2$ ), three $\mathrm{CCD}$ arrays per band are combined to generate about 6000 pixels per row. A complete coverage cycle of the CCD camera takes 26 days. A similar camera is also aboard CBERS-2B.

\section{Spatial resolution}

Spatial resolution is an important parameter that allows an objective assessment of the imaging system performance. In general, the term "spatial resolution" determines the degree to which fine detail can be observed in an image. More precisely, resolution is the smallest distance between two objects that can be distinguished in the image (Mather, 1999).

Effective Instantaneous Field of View (EIFOV) is the most used parameter to measure spatial resolution. EIFOV is defined as the resolution corresponding to a spatial frequency (ground resolution) for which the system MTF is $50 \%$. It is used to measure the system performance and defined as a function of the sensor. Moreover, the EIFOV parameter enables a comparison among different sensors with similar nominal spatial resolution (linear IFOV), i.e., geometric size of the image projected by the detector on the ground through the optical system.

Another important parameter is MTF, Fourier transform of the impulse response (PSF). MTF is a result of cumulative effects of instrument optics (diffraction, aberration, focusing error), integration on a 
photosensitive surface, charge diffusion along the array and image motion induced by the movement of the satellite during imaging. Generally, MTF is considered as an indicator of how sharp the edges of any object are after contrast reduction during imaging. However, MTF is also a measure of how accurately the actual radiance from a pixel is measured, since a lower MTF indicates contribution from other pixels to the pixel under observation (and vice versa) (Morain and Budge, 2004).

Therefore, the MTF of CBERS cameras are parts of image quality parameters assessed during the commissioning phase and during the satellite life cycle. Besides, MTF has been used to adjust the restoration filters used to improve CBERS image quality (see, for example, Banon and Fonseca (1998)). In general MTF or PSF can be approximated by a Gaussian function (Luxen and Forstner, 2002). When PSF is approximated by a Gaussian function with standard deviation $\sigma$, the EIFOV is $2.66 \sigma$ (Slater, 1980; Banon, 1990; Banon and Santos, 1993). The relation between the EIFOV parameter and the normalized graph of a Gaussian MTF $H$ is illustrated in Figure 1.

The main idea of the three proposed methods to estimate the effective spatial resolution are the same. Once the striping effect has been removed, the methods consist of creating a simulated image of the target and calculating a distance between this image and the target real image. The desired parameter of the imaging system model, or, equivalently, the effective spatial resolution, is obtained when this distance is minimum, that is, when the blurring effect of the target simulated image and the blurring effect of the target real image are the same. In the methods of Sections 4 and 5, the target simulated image is obtained by computing the convolution between a function that describes the actual radiometry and geometry of the target, and a Gaussian function that models the imaging system response. In the method of Section 6, the target simulated image is obtained by computing the convolution between a higher resolution image of the target, and a Gaussian function that models a low pass filter.

\section{Spatial resolution estimation using an artificial target}

The first experiment uses an artificial target set up on the ground in the Gobi desert (China). The PSF is modelled as 2D Gaussian function that is characterized by two parameters corresponding to along and 
across-track directions. The target image simulation is performed from the target model in order to find the optimal parameters that characterize the CCD camera PSF. Details about target image, digital target model, and target image simulation, are given in the next sections.

\subsection{Target image}

The target is a dark squared tarp placed in the Gobi desert. The test site is situated at about $35 \mathrm{~km}$ west of Dunhuang city in Gansu Province, China. Its location is about $30 \mathrm{~km}$ from south to north and $40 \mathrm{~km}$ from east to west, and its size is $60 \mathrm{~m} \times 60 \mathrm{~m}$, which corresponds to a sub-image of $3 \times 3$ pixels. Furthermore, the black target edge is aligned with the along track direction of the satellite.

The target images used in this experiment were acquired by CBERS-1 on 4 September 2000 and by CBERS-2 on 19 August 2004. Figure 2 shows the black target in the centre of the image (CBERS-1, Band 3). In order to make visualization easier, the image was zoomed up. In this experiment, only Bands B2, $\mathrm{B} 3$, and B4 were processed.

The raw CBERS-1 images (without calibration) present a striping effect: odd columns are brighter than even columns (Figure 2). The images are processed in order to remove the striping effect by adjusting the mean and standard deviation of the odd and even columns as described in Banon (2000).

Let $E$ be the image domain with an even number of columns. Let $E_{1}$ and $E_{2}$ be the sets of pixel positions belonging, respectively, to the odd and even columns of $E$. Let $f$ be the original CBERS- 1 image. The destriped image $g$ is given by:

$$
g(x)=\left\{\begin{array}{ll}
a_{1} f(x)+b_{1} & \text { if } x \in E_{1} \\
a_{2} f(x)+b_{2} & \text { if } x \in E_{2}
\end{array}, \quad x \in E\right.
$$

where

$$
a_{1}=\frac{s}{s_{1}}, a_{2}=\frac{s}{s_{2}}, b_{1}=m-a_{1} \cdot m_{1}, b_{2}=m-a_{2} \cdot m_{2}
$$


and $m_{1}$ and $m_{2}$ are the mean values of the original image restricted to $E_{1}$ and $E_{2}$, respectively. $s_{1}$ and $s_{2}$ are the standard deviations of the original image restricted to $E_{1}$ and $E_{2}$, respectively, and $m=\left(m_{1}+m_{2}\right) / 2$ and $s=\left(s_{1}+s_{2}\right) / 2$. After the processing, one can observe (Figure 3$)$ that the striping effect has been completely eliminated without removing the target information.

\subsection{Digital target model}

Let $\mathbf{Z}$ be the set of integer numbers and let $\mathbf{Z}^{2}$ be the Cartesian product of $\mathbf{Z}$ by itself. Let $x \in \mathbf{Z}$, we denote by $\underline{x}$ the pair $(x, x)$ of $\mathbf{Z}^{2}$. For example $\underline{10}$ stands for the $\operatorname{pair}(10,10)$. Let $F$ be a finite square of $\mathbf{Z}^{2}$ (i.e., the Cartesian product of two finite intervals of $\mathbf{Z}$, of the same size) with an odd number of lines and columns representing the digital scene domain in which the distance between two consecutive horizontal or vertical points is one meter, for convenience. Let $u$ be the centre of $F$. Based on target radiometric and geometric features, the digital target model is the function $f_{t}$ on $F$, for every $x \in F$, given by:

$$
f_{t}(x)= \begin{cases}t & \text { if } x \in[u-\underline{30}, u+\underline{30}], \\ s & \text { otherwise, }\end{cases}
$$

where $s$ and $t$ are the background (desert) and the target radiometry values, respectively. $[a, b]$ is the rectangle of $\mathbf{Z}^{2}$ having $a$ as lower left corner and $b$ as upper right corner. One observes that the digital target model is centred at $u$ and the target size is $61 \mathrm{~m} \times 61 \mathrm{~m}$ (Figure 4).

\subsection{Target image simulation}

Let $G$ be a finite square of $\mathbf{Z}^{2}$ with an odd number of rows and columns, representing the target image domain. Let $v$ be the centre point of $G$ and let $T_{k}$ be a geometric transformation from $G$ to $F$ given by:

$$
T_{k}(y)=20(y-v)+u+k
$$

for every y $\in G$ and $k \in \mathbf{Z}^{2}$.

The transformation $T_{k}$ is the system geometric model, where the value 20 represents the distance (in meter) between two consecutive horizontal or vertical pixel positions (sampling rate). The offset $k$ defines how 
far the transformation of the target image domain centre $v$ is from the digital scene domain centre $u$ (Figure 4). By assuming that the imaging system is linear, the simulated image of the target is

$$
\left(f_{t} * h\right) \circ T_{k} \text {, }
$$

where $h$ is the sensor PSF, * is the (circular) convolution product ( $u$ being chosen as the origin) on $F$, and - is the mapping composition. By composition definition, one can observe that the target simulated image is a function on $G$.

\subsection{PSF identification}

The CBERS CCD point spread function is modeled as a separable 2D Gaussian function $h_{\sigma_{1}, \sigma_{2}}$ on $F$, with centre at $\left(u_{1}, u_{2}\right)$, that is, for every $\left(x_{1}, x_{2}\right) \in F$,

$$
h_{\sigma_{1}, \sigma_{2}}\left(x_{1}, x_{2}\right)=\frac{1}{2 \pi \sigma_{1} \sigma_{2}} e^{-\left(\frac{\left(x_{1}-u_{1}\right)^{2}}{2 \sigma_{1}^{2}}+\frac{\left(x_{2}-u_{2}\right)^{2}}{2 \sigma_{2}^{2}}\right)},
$$

where $\sigma_{1}$ and $\sigma_{2}$ are the standard deviation of the Gaussian model.

Let the root mean square difference between $f_{t}$ and $g, \operatorname{RMS}\left(f_{t}, g\right)$, be the real number given by

$$
\operatorname{RMS}\left(f_{t}, g\right)=\left(\sum_{y \in G}\left(\left(f_{t} * h_{\sigma_{1}, \sigma_{2}}\right)\left(T_{k}(y)\right)-g(y)\right)^{2}\right)^{1 / 2} .
$$

Let $g$ be the target image defined on $G$, so that $g(v)$ has the lowest (recall that the target is black) value among all the pixel values of $g$. The PSF identification consists of finding $\sigma_{1}$ and $\sigma_{2}$ so that $g$ and $\left(f_{t} * h_{\sigma_{1}, \sigma_{2}}\right) \circ T_{k}$ best fit under the root mean square criteria.

The PSF identification is a two-step procedure. In the first step, $t=g(v)$ and one looks for $k, \sigma_{1}$ and $\sigma_{2}$, which minimize $\operatorname{RMS}\left(f_{t}, g\right)$. Because $g(v)$ is the lowest value among the pixel values of $g$, the domain of $k$ reduces to $[-10, \underline{10}]$ of $\mathbf{Z}^{2}$.

In the second step, one uses the previous optimum $k=\left(k_{1}, k_{2}\right)$ and looks for $t, \sigma_{1}$ and $\sigma_{2}$ which minimize $\operatorname{RMS}\left(f_{t}, g\right)$. The block diagram shown in Figure 5 illustrates the PSF identification process. The desert radiometry $s$ was estimated by averaging the pixel values in the target neighborhood. 
In the above procedure, we used $F=[1,241], u=121, G=[1,11], v=6$. The target radiometry value $t$ was considered within the interval $[g(v)-2, g(v)+2]$ of $\mathbf{Z}$.

Finally, the optimal values of $\sigma_{1}$ and $\sigma_{2}$ were obtained by nonlinear programming (Himmelblau, 1972).

\subsection{Results}

Tables 2 and 3 show the spatial resolution values, in the across-track direction, measured before launching CBERS-1 and CBERS-2 respectively. Generally, the EIFOV values are similar in the along and acrosstrack directions in the pushbroom sensors. Similarly to the movement of the satellite during imaging in the along-track direction, the electronic aberrations in the across-track direction also introduces a blurring effect into the images. Hence, in this study we consider that the pre-flight spatial resolution values in both directions are approximately equal for Bands 2 and 3.

In Tables 2 and 3, the EIFOV values of Band 4 are much higher than those of Bands 2 and 3. This blurring effect in the CBERS-1 Band 4 was observed during the satellite integration tests and is due to a problem in the camera assembly. The same blurring effect was observed for the CBERS-2 Band 4 although assembly problem was solved. It was expected that this camera assembly problem would affect only the MTF in the across-track direction. Therefore, the MTF in the along-track direction was expected to be better than that in the other direction.

Tables 4 and 5 show the estimated EIFOV values, respectively for CBERS- 1 and CBERS-2, in the alongand across-track directions. We can observe that, in some sense, the EIFOV values in the across-track direction are worse than those of the specifications for both sensors CBERS-1 and CBERS-2, and therefore are not in accord with the pre-flight measurements. Moreover, the EIFOV values obtained in the across-track direction for Bands 2 and 3 are very much worse than the expected ones. On the other hand, EIFOV values in the along-track direction, for CBERS-1 and CBERS-2 are better than those in the acrosstrack direction. We observed a significant improvement in the spatial resolution of CBERS-2 images in relation to CBERS-1 for all bands except for Band 3 in the along-track direction. 
Figures 6 and 7 show the along-track and the across-track fitting between the original data and the simulated data for Band 3.

\section{Natural target}

This experiment uses bridges as targets. Two bridges are used to estimate the PSF in both directions: along and across-track. The PSF identification is accomplished in three steps: bridges modelling, bridge axis identification and bridge image simulation of the bridge model. These steps are described in the following sections.

\subsection{Target Images}

The Rio-Niterói bridge over Guanabara Bay was chosen as target for the estimation of the spatial resolution in the along-track direction. This bridge is $13.29 \mathrm{~km}$ long, with only one deck, and 26.6 meters wide. In order to estimate the spatial resolution in the across-track direction, the Causeway bridge over the Pontchartrain lake was used. This bridge is constituted of two decks and a gap between them. It is 38.62 $\mathrm{km}$ long, where each deck is 10.0 meters wide, with a 24.4 meters wide gap. The two decks were constructed at different times (1956 and 1969) and exhibit slightly different reflectance values. In addition, the water background is reasonably uniform.

The Rio-Niterói bridge images were acquired by CBERS-1 on 2 December 2001 and by CBERS-2 on 10 July 2004. The Lake Pontchartrain Causeway bridge images were acquired by CBERS-1 on 6 October 2002 and by CBERS-2 on 25 September 2004.

The red rectangles (Figures 8 and 9) show the sub-images selected for the experiment. Figures $10(a)$ and 11(a) show the original Rio-Niterói bridge and Causeway bridge images (Band 3), respectively. As the images are not calibrated, they present a striping effect. Using the algorithm described in the section 4.1, the raw images were de-striped. Figures $10(b)$ and $11(b)$ show the bridge images after being processed. In order to make visualization easier, the images were enhanced and zoomed up. 


\subsection{Digital bridge model}

\section{Rio-Niterói bridge}

Let $\mathbf{Z}$ be the set of integer numbers. Let $F_{1}$ be a finite interval of $\mathbf{Z}$ with an odd number of elements, which represents a vertical line of the digital scene domain. The distance between two consecutive elements is one meter, for convenience.

Let $u_{1}$ be the centre of $F_{1}$. Based on its radiometric and geometric features, the bridge over the Guanabara bay, is modeled as the function $f_{1}$ on $F_{1}$ given by, for every $x \in F_{1}$ :

$$
f_{1}(x)= \begin{cases}t & \text { if } x \in\left[u_{1}-13, u_{1}+13\right] \\ s & \text { otherwise }\end{cases}
$$

where $s$ and $t$ are the background (water body) and the deck radiometry, respectively.

\section{Causeway bridge}

Let $F_{2}$ be a finite interval of $\mathbf{Z}$ with an even number of elements representing a horizontal line of the digital scene domain. For convenience, the distance between two consecutive elements is one meter. Let $u_{2}$ be the centre of $F_{2}$. Based on its radiometric and geometric features, the bridge over the Pontchartrain lake, is modeled as the function $f_{2}$ on $F_{2}$ given by, for every $x \in F_{2}$ :

$$
f_{2}(x)= \begin{cases}t_{1} & \text { if } x \in\left[u_{2}-22, u_{2}-13\right] \\ t_{2} & \text { if } x \in\left[u_{2}+13, u_{2}+22\right] \\ s & \text { otherwise }\end{cases}
$$

where $s, t_{1}$ and $t_{2}$ are the background, left deck and right deck radiometry values, respectively.

\subsection{Bridge axis identification}

According to Figures 10 and 11, the bridge axis is a straight line. Consequently, it can be represented by a linear model. Let the bridge image $g$ be a mapping from $G=\mathbf{m} \times \mathbf{n}$, its domain, to $K$, its gray-scale, where $\mathbf{m}=[1, m] \subset \mathbf{Z}$ and $\mathbf{n}=[1, n] \subset \mathbf{Z} . m$ and $n$ are the number of rows and columns of the image $g$, respectively. 


\section{Rio-Niterói bridge}

Let $c_{1}$ be the mapping from $\mathbf{n}$ to $\mathbf{m}$ so that $c_{1}(j)(j \in \mathbf{n})$ is the row number in $\mathbf{m}$, for which $g\left(c_{1}(j), j\right)$ is maximum in $\{g(i, j)\}_{i \in \mathbf{m}}$. Let $a, b \in \mathbf{R}$, so that $\sum_{j \in \mathbf{n}}\left((a j+b)-c_{1}(j)\right)^{2}$ is minimum, then $a j+b(j \in \mathbf{n})$ is the bridge centre estimation along column $j$.

\section{Causeway bridge}

Let $c_{2}$ be the mapping from $\mathbf{m}$ to $\mathbf{n}$ so that $c_{2}(i)(i \in \mathbf{m})$ is the column number in $\mathbf{n}$, for which $g\left(i, c_{2}(i)\right)$ is maximum in $\{g(i, j)\}_{j \in \mathbf{n}}$. Let $a, b \in \mathbf{R}$, so that $\sum_{i \in \mathbf{m}}\left((a i+b)-c_{2}(i)\right)^{2}$ is minimum, then $a i+b(i \in \mathbf{m})$ is the bridge centre estimation along row $i$. In both cases (Rio-Niterói and Causeway bridge), there are more measurements available than unknown parameters ( $a$ and $b$ ). Therefore, the QR-decomposition was used to generate a least square solution of an over-determined system of linear equations (Kreyszig, 1993).

\subsection{Bridge image simulation}

\section{Rio-Niterói bridge}

The procedures for the bridge image simulation are based on the estimation of bridge centre described in the Section 4.3 .

For a given column $j \in \mathbf{n}$, let $\hat{c}_{1}=a j+b$. Let $G_{1}$, be a finite interval of $\mathbf{Z}$ with an odd number of elements, denoted by $p$. Let $v=(p+1) / 2$ be the centre of $G_{1}$. Let us assume that $G_{1}+\left\lfloor\hat{c}_{1}+\frac{1}{2}\right\rfloor-v \subset \mathbf{m}$, where $\lfloor x\rfloor$ is the integer part of $x$.

Let $T_{k_{1}}$ be the geometric transformation from $G_{1}$ to $F_{1}$ given by, for every $y \in G_{1}$ :

$$
T_{k_{1}}(y)=\left\lfloor 20(y-v)+\frac{1}{2}\right\rfloor+u_{1}+k_{1},
$$


where $k_{1}=\left\lfloor 20\left(\left\lfloor\hat{c}_{1}+\frac{1}{2}\right\rfloor-\hat{c}_{1}\right)+\frac{1}{2}\right\rfloor$.

In the above definition, $u_{1}$ is the centre of the bridge, and $k_{1}$ represents how far the transformation of $v$ is from $u_{1}$. Figure 12 shows the Rio-Niterói bridge model.

\section{Causeway bridge}

This simulation is similar to the one of Rio-Niterói bridge. For a given row $i \in \mathbf{m}$, let $\hat{c}_{2}=a i+b$. Let $G_{2}$, be a finite interval of $\mathbf{Z}$ with an even number of elements, denoted $p$. Let assume that $G_{2}+\left\lfloor\hat{c}_{2}\right\rfloor-\frac{p}{2} \subset \mathbf{m}$.

Let $T_{k_{2}}$ be a geometric transformation from $G_{2}$ to $F_{2}$ given by, for every $y \in G_{2}$ :

$$
T_{k_{2}}(y)=20(y-v)+u_{2}+k_{2},
$$

where $v=p / 2$ is the centre of $G_{2}, u_{2}$ is the centre of the bridge and $k_{2}$ represents how far the transformation of $v$ is from $u_{2}$.

In the Causeway bridge image simulation, the bridge centre estimation $\hat{c}_{2}$ is biased due to the different radiometry values of the two decks. Accordingly, $k_{2}$ is expressed as $k_{2}=k_{2}^{\prime}+\delta$ where $k_{2}^{\prime}=\left\lfloor 20\left(\frac{1}{2}+\left\lfloor\hat{c}_{2}\right\rfloor-\hat{c}_{2}\right)+\frac{1}{2}\right\rfloor$ and $\delta$ is a corrective term that takes into account the bridge centre estimation bias. Since $\delta$ assumes only a few integer values, its estimation can be based on an exhaustive search. Figure 13 shows the Causeway bridge model.

\subsection{PSF identification}


Similar to Section 3.4, the PSF is modeled as a 2D separable Gaussian function $h_{\sigma_{1}, \sigma_{2}}$ on $F_{1} \times F_{2}$ centred at $\left(u_{1}, u_{2}\right)$, that is, $h_{\sigma_{1}, \sigma_{2}}\left(x_{1}, x_{2}\right)=h_{\sigma_{1}}\left(x_{1}\right) h_{\sigma_{2}}\left(x_{2}\right)$, where, for every $x_{1} \in F_{1}, h_{\sigma_{1}}\left(x_{1}\right)=\frac{1}{\sqrt{2 \pi} \sigma_{1}} e^{-\frac{\left(x_{1}-u_{1}\right)^{2}}{2 \sigma_{1}^{2}}}$, and for every $x_{2} \in F_{2}, h_{\sigma_{2}}\left(x_{2}\right)=\frac{1}{\sqrt{2 \pi} \sigma_{2}} e^{-\frac{\left(x_{2}-u_{2}\right)^{2}}{2 \sigma_{2}^{2}}}$.

Let $g_{1}^{j}$ be the $j^{\text {th }}$ bridge image column defined on $G_{1}$ given by

$$
g_{1}^{j}(y)=g\left(\left\lfloor\hat{c}_{1}+\frac{1}{2}\right\rfloor-v+y, j\right)
$$

and let $g_{2}{ }^{i}$ be the $i^{\text {th }}$ bridge image row defined on $G_{2}$ given by

$$
g_{2}^{i}(y)=g\left(i,\left\lfloor\hat{c}_{2}\right\rfloor-\frac{p}{2}+y\right)
$$

The PSF identification in the along-track direction consists of finding $\sigma_{1}$ so that $g_{1}{ }^{j}$ and $\left(f_{1} * h_{\sigma_{1}}\right) \circ T_{k_{1}}$ best fit under the root mean square criteria. In the same way, the PSF identification in the across-track direction consists of finding $\sigma_{2}$ so that $g_{2}{ }^{i}$ and $\left(f_{2} * h_{\sigma_{2}}\right) \circ T_{k_{2}}$ best fit under the root mean square criteria.

Let $\mathrm{RMS}_{1}$ be the real number given by

$$
\operatorname{RMS}_{1}=\left(\sum_{y \in G_{1}}\left(\left(f_{1} * h_{\sigma_{1}}\right)\left(T_{k_{1}}(y)\right)-g_{1}^{j}(y)\right)^{2}\right)^{1 / 2} .
$$

The along-track estimation procedure is performed in two steps. Firstly, we look for $t, s$ and $\sigma_{1}$ that minimize $\mathrm{RMS}_{1}$. Afterwards, using their mean values over all columns obtained from the first step, one looks for $\sigma_{1}$ that minimizes $\mathrm{RMS}_{1}$.

Let $\mathrm{RMS}_{2}$ be the real number given by 


$$
\mathrm{RMS}_{2}=\left(\sum_{y \in G_{2}}\left(\left(f_{2} * h_{\sigma_{2}}\right)\left(T_{k_{2}}(y)\right)-g_{2}^{i}(y)\right)^{2}\right)^{1 / 2} .
$$

The across-track estimation procedure is also performed in two steps. First of all, one looks for $\delta, t_{1}, t_{2}, s$ and $\sigma_{2}$ that minimizes $\mathrm{RMS}_{2}$. Secondly, using their mean values over all rows obtained from the first step, we look for $\sigma_{2}$ that minimize $\mathrm{RMS}_{2}$.

For both simulations (in the along-track and across-track-directions) the optimum values of $\sigma_{1}$ and $\sigma_{2}$ have been obtained by nonlinear programming (Himmelblau, 1972).

\subsection{Results}

Tables 6 and 7 show the estimated EIFOV values of CBERS-1 and CBERS-2, respectively. The results confirm that the spatial resolution values in the across-track direction, for all bands, are worse than those in the along-track direction. The results are slightly different from those obtained from the first method. The bridge method seems to be a little more pessimist than the target method. However, some differences are expected since the data used in the experiment was acquired at different dates and under different atmospheric conditions.

\section{Spatial resolution estimation using higher resolution images}

The third experiment uses two images: a CBERS CCD image and a higher resolution one of the same scene acquired by the SPOT-4 satellite. The method is iterative and the goal is to find a parameter of a low-pass filter that minimizes the Root Mean Square (RMS) difference between the CBERS and the filtered SPOT-4 images. Initially, the target images are selected and pre-processed to remove the striping effect. Then, the two images (CBERS and SPOT-4) are registered so that the same objects on the ground appear in the same position on the registered images. 


\subsection{Target selection and data preparation}

In this case, the same targets as the ones used for the experiments described Section 4 were selected. CBERS-1 and CBERS-2 images of Rio-Niterói and Causeway bridges were selected. Furthermore, SPOT4 images were acquired on 28 November 2001 (Rio-Niterói bridge) and on 25 November 2002 (Causeway bridge) and are illustrated in Figures 14 and 15, respectively.

Despite the fact that some of the above sets of images were acquired almost three years apart, they could be used because the targets used in the experiments remained almost unchanged during this period of time. CBERS and SPOT images were registered using an automatic image registration system (Fedorov et al., 2003, 2006). SPOT-4 images were taken as reference images in the registration process. Figures 16 and 17 show the results after the registration process.

\subsection{PSF identification}

As in the previous sections, the point spread function is modeled as a 2D separable Gaussian function. In this experiment, the EIFOV estimation method is based on the degradation of SPOT-4 image so that its spatial resolution is similar to that of CBERS image (lower resolution). CBERS and SPOT-4 images must be well registered and the EIFOV value for each band of SPOT images must be known.

Let $f$ be the original scene and let $h_{\mathrm{s}}$ be the SPOT-4 imaging system PSF. Then, the original SPOT-4 image is given by:

$$
g_{\mathrm{s}}=h_{\mathrm{s}} * f .
$$

Let $h_{\mathrm{d}}$ be the degradation filter PSF. Then SPOT-4 degraded image is given by:

$$
g_{\mathrm{d}}=h_{\mathrm{d}} * g_{\mathrm{s}}=h_{\mathrm{d}} *\left(h_{\mathrm{s}} * f\right)=\left(h_{\mathrm{d}} * h_{\mathrm{s}}\right) * f \text {. }
$$

Finally, let $h_{\mathrm{c}}$ be CBERS CCD point spread function. Therefore, CBERS image is given by:

$$
g_{\mathrm{c}}=h_{\mathrm{c}} * f .
$$


To find CBERS PSF $h_{\mathrm{c}}$, one minimizes the root mean square difference between CBERS image $g_{\mathrm{c}}$ and SPOT-4 degraded image $g_{\mathrm{d}}$ by adjusting $h_{\mathrm{d}}$. At the minimum, $g_{\mathrm{d}} \approx g_{\mathrm{c}}$ and $h_{\mathrm{s}} * h_{\mathrm{d}}$ is the estimation for $h_{\mathrm{c}}$. Figure 18 shows the block diagram of the low-resolution image simulation process and the root mean square error computation.

For the along- and across-track spatial resolution estimation, a three-step adjustment was performed. The first one consists of estimating a gain parameter to adjust the radiometry between CBERS and SPOT-4 images. The second step consists of finding an offset parameter that describes the residual registration error between both images. In the last step, the standard deviation parameter of the degradation filter is estimated and used to compute CBERS EIFOV values. In all steps the root-mean-square minimization is performed. Details about the method are presented below.

Let $g_{\mathrm{c}}$ be one column (one line) of CBERS Rio-Niterói (Causeway) bridge image and $g_{\mathrm{s}}$ be one column (one line) of SPOT-4 Rio-Niterói (Causeway) bridge image.

Let denote by $g_{\mu, \sigma}$ the degraded SPOT-4 image column (one line) that is:

$$
g_{\mu, \sigma}=h_{\mathrm{d}} * g_{\mathrm{s}},
$$

where $h_{\mathrm{d}}(x)=\frac{1}{\sqrt{2 \pi} \sigma} e^{-\frac{(x-\mu)^{2}}{2 \sigma^{2}}}$.

\section{Step 1: Radiometric Adjust}

In this step, the radiometric adjustment consists of estimating the gain parameter $a$ that minimizes the root mean square difference between CBERS image column (line) and SPOT-4 image column (line). Hence, given an a priori value $\sigma_{0}$ we look for the parameter $a$ that minimizes

$$
\sum\left(\left(a g_{\mathrm{c}}+b\right)-g_{0, \sigma_{0}}\right)^{2}
$$


Where $b=m-a m_{\mathrm{c}}$ (the initial value for $a$ is $s / s_{\mathrm{c}}$ ), $m_{\mathrm{c}}$ and $s_{\mathrm{c}}$ are the mean and standard deviation of $g_{\mathrm{c}}$, and $m$ and $s$ are the mean and standard deviation of $g_{s}$.

\section{Step 2: Offset Adjust}

In this step, given the parameters $a$ and $b$ determined at step 1, one looks for $\mu$ that minimizes

$$
\sum\left(\left(a g_{c}+b\right)-g_{\mu, \sigma_{0}}\right)^{2}
$$

\section{Step 3: EIFOV Estimation}

In this step, after the parameters $a, b$ and $\mu$ have been determined, one looks for $\sigma$ that minimizes

$$
\sum\left(\left(a g_{c}+b\right)-g_{\mu, \sigma}\right)^{2} .
$$

Therefore, given the $\sigma$ parameter and the effective spatial resolution $\left(\mathrm{EIFOV}_{\mathrm{s}}\right)$ of SPOT-4 image, CBERS CCD effective spatial resolution $\left(\mathrm{EIFOV}_{\mathrm{c}}\right)$ is calculated by:

$$
\operatorname{EIFOV}_{\mathrm{c}}=2.66\left(\left(\frac{\mathrm{EIFOV}_{\mathrm{s}}}{2.66}\right)^{2}+\sigma^{2}\right)^{1 / 2},
$$

where EIFOV $\mathrm{s}$ is the along-track (across-track) spatial resolution of SPOT-4 system. The final EIFOV value is taken as the mean value of EIFOV $_{\mathrm{c}}$ over all columns (or lines).

In the three steps described above, the parameters have been obtained by nonlinear programming (Himmelblau, 1972).

\subsection{Results}

The EIFOV values of SPOT-4 system used in our experiments are shown in Table 8. The estimated parameters of the CBERS- 1 and CBERS-2 cameras are presented in Tables 9 and 10, respectively. The results are similar to those obtained by the methods based on artificial and natural targets. 


\section{Final Considerations}

In order to evaluate the results obtained in this work, we have compared them with those obtained by J. Jun Sun (personal communication, 2004). He has estimated the EIFOV values for CBERS-2 CCD camera. Table 11 presents the mean EIFOV values obtained by him. In order to compare our results with his, the mean EIFOV values (CBERS-2) obtained from the three experiments were calculated and are shown in Table 12. From Tables 11 and 12 we observe that the EIFOV values in the across-track direction are worse than those in the along-track direction for both approaches. Besides, the EIFOV values in the across-track direction obtained by our approach are somewhat larger than the ones obtained by J. Jun Sun (personal communication, 2004). Considering that the data and the methodologies used in the experiments are different, it is very difficult to further compare these results. However, in both experiments we observed that the EIFOV values in the across-track direction are worse than those of the specifications for both CBERS-1 and CBERS-2 sensors.

\section{Conclusion}

In this paper, the spatial resolution of CBERS-2 is computed from target images, using three different approaches, and compared to the spatial resolution of CBERS-1 that was already known. The estimation process consists of finding the best fit between the image acquired by the sensor, and a simulated image. The targets used in the experiments were bridges and an artificial target placed in the Gob Desert (China). In all experiments the results showed that the spatial resolution does not conform to the specification for all bands of CBERS-1 and CBERS-2, mainly in the across-track direction. This problem might be explained by the vibration effect provoked when both IRMSS and CCD sensors work simultaneously or by the electronic coupling between adjacent detectors. As expected, the spatial resolution of CBERS-1 Band 4, in across-track direction, is not in accord with the camera specification. Broadly speaking, CBERS-2 CCD camera presented better performance in terms of spatial resolution than that of CBERS-1 CDD camera. 
The algorithms developed in this work have been implemented in a CBERS Image Processing System as part of a module that is responsible for evaluating the quality of CBERS images. They have been used to estimate the CBERS cameras EIFOV values during the in-flight commissioning phase and during the satellite life cycle in order to control the quality of the images produced by CBERS cameras. Based on these estimations it is possible to improve the image quality using restoration algorithms.

\section{References}

BANON, G.J.F., 2000, Formal introduction to digital image processing (São José dos Campos: INPE). INPE-7682-PUD/097. Available online at: http://urlib.net/dpi.inpe.br/banon/1999/06.21.09.31 (accessed 1 November 2006).

BANON, G.J.F., 1990, Simulação de imagens de baixa resolução. Controle \& Automação, 2(3), 180-192

BANON, G.J.F. and FONSECA, L.M.G., 1998, CBERS simulation from SPOT and its restoration (São José dos Campos: INPE). Available online at: http://urlib.net/dpi.inpe.br/banon/1998/05.18.09.47 (accessed 1 November 2006).

BANON, G.J.F. and SANTOS, A.C., 1993, Digital filter design for sensor simulation: application to the Brazilian Remote Sensing Satellite (São José dos Campos: INPE). INPE-5523- RPQ/665. Available online at: http://urlib.net/dpi.inpe.br/banon/1995/12.14.18.12 (accessed 1 November 2006).

BENSEBAA, K., BANON, G.J.F. and FONSECA, L.M.G., 2004a, On orbit spatial resolution estimation of CBERS-1 CCD camera. In Proceedings of the Third International Conference on Image and Graphics (ICIG) , Hong Kong, China, 2004, pp. 576-579. doi: 10.1109/ICIG.2004.109. 
BENSEBAA, K., BANON, G.J.F. and FONSECA, L.M.G., 2004b, On-orbit spatial resolution estimation of CBERS-1 CCD imaging system from bridge images. In Proceedings of the Twentieth ISPRS Congress, Istanbul, Turkey, 2004. v. XXXV-B1, pp. 36-41. ISSN 1682-1750. INPE-11413-PRE/6849. Available online at: http://www.isprs.org/istanbul2004/comm1/papers/7.pdf (accessed 10 November 2006).

BENSEBAA, K., BANON, G.J.F. and FONSECA, L.M.G, 2005, On-orbit spatial resolution estimation of CBERS-1 CCD imaging system using higher resolution images. In Anais do Décimo Segundo Simpósio Brasileiro de Sensoriamento Remoto (SBSR), Goiânia,GO, Brazil, 2005 (São José dos Campos: INPE), pp. 827-834. ISBN 85-17-00018-8. INPE-12612-PRE/7905. Available online at: http://urlib.net/ltid.inpe.br/sbsr/2004/11.19.19.28 (accessed 10 November 2006).

CHOI, T., 2003. IKONOS satellite on orbit modulation transfer function (MTF) measurement using egde and pulse method. Master's Thesis, South Dakota State University, Brookings, SD.

CHOI, T. and HELDER, D., 2003, On-orbit Modulation Transfer Function (MTF) measurement of IKONOS. In Proceedings of the 2003 High Spatial Resolution Commercial Imagery Workshop, Reston, VA, USA, 2003 (CD-ROM; sponsored by NASA/NIMA/USGS JACIE Team).

FEDOROV, D., FONSECA, L.M.G., KENNEY, C. and MANJUNATH, B.S., 2003 Automatic registration and mosaicking system for remotely sensed imagery. In Anais do Décimo Primeiro Simpósio Brasileiro de Sensoriamento Remoto, Belo Horizonte, Brazil, 2003 (São José dos Campos: INPE), pp. 317-324. ISBN 85-17-00017-X. INPE-10534-PRE/6006. Available online at: http://urlib.net/ltid.inpe.br/sbsr/2002/11.18.09.27 (accessed 22 October 2006). 
FEDOROV, D., FONSECA, L.M.G., KENNEY, C. and MANJUNATH, B.S., 2006, Automatic Registration and Mosaicking System. Available online at: http://regima.dpi.inpe.br (accessed 20 April 2006).

FONSECA, L.M.G., PONZONI, F. and CARTAXO, R., 2004, Radiometric quality assessment of CBERS-2 (São José dos Campos: INPE) APPL-06-2004. Available online at: http://urlib.net/dpi.inpe.br/banon/2006/08.03.19.18 (accessed 23 September 2006).

FONSECA, L.M.G., ESCADA, J, and PONZONI, F., 2002, A Preliminary assessment of geometric and radiometric quality for CBERS-1 CCD instrument (São José dos Campos: INPE) APPL-02-2002.

FONSECA, L.M.G. and MASCARENHAS, N.D.D., 1987, Determinação da função de transferência do sensor TM do satelite Landsat-5. In Resumos dos Trabalhos do Décimo Congresso Nacional de Matematica Aplicada e Computacional, Gramado, Brazil, 1987, pp. 297-302. INPE-4213-PRE/1094.

HIMMELBLAU, D.M., 1972, Applied nonlinear programming (New York: McGraw-Hill).

KREYSZIG, E., 1993, Advanced engineering mathematics (New York: John Wiley and Sons).

LEGER, D., VIALLEFONT, F., HILLAIRET E. and MEYGRET, A., 2003, In-flight refocusing and MTF assessment of SPOT5 HRG and HRS cameras. In Sensors, Systems, and Next-Generation Satellites VI, Agia Pelagia, Crete, Greece, 2002, H. Fujisada, J.B. Lurie, M.L. Aten and K. Weber (Eds.) (Bellingham: SPIE), v. 4881, pp. 224-231. doi: 10.1117/12.462639. 
LUXEN, M. and FORSTNER, W., 2002, Characterizing image quality: Blind estimation of the point spread function from a single image. In Proceedings of the ISPRS Congress, Graz, Austria, 2002, v. XXXIV-3A, pp. 205-210.

MARKHAM, B.L., 1985, The Landsat sensor's spatial response. IEEE Transactions on Geoscience and Remote Sensing, 23(6), 864-875.

MATHER, P.M., 1999, Computer processing of remotely-sensed images: an introduction (Chichester: John Wiley).

MORAIN, S.A. and BUDGE, A.M., Eds., 2004, Post-Launch Calibration of Satellite Sensors. ISPRS Book series (London, Taylor and Francis).

NELSON, N.R. and BARRY, P.S., 2002, Measurement of hyperion MTF from on-orbit scenes. In Imaging Spectrometry VII, San Diego, CA, USA, 2001, M.R. Descour and S.S. Shen (Eds.) (Bellingham: SPIE), v. 4480, pp. 236-241. doi: 10.1117/12.492672.

SLATER, P.N., 1980, Remote sensing optics and optical system (London: Addison-Wesley).

STOREY, J.C., 2001, Landsat 7 on-orbit modulation transfer function estimation. In Sensors, Systems, and Next-Generation Satellites V, Toulouse, France, 2001, H. Fujisada, J.B. Lurie and K. Weber (Eds.) (Bellingham: SPIE), v. 4540, pp. 50-61. doi: 10.1117/12.450647. 
Table 1. Spectral bands of the CCD sensor.

\begin{tabular}{c|c|c}
\hline $\begin{array}{c}\text { Spectral } \\
\text { Bands }\end{array}$ & $\begin{array}{c}\text { Band } \\
\text { Number }\end{array}$ & $\begin{array}{c}\text { Wavelength } \\
(\mu \mathrm{m})\end{array}$ \\
\hline Blue & 1 & $0.45-0.52$ \\
\hline Green & 2 & $0.52-0.59$ \\
\hline Red & 3 & $0.63-0.69$ \\
\hline Near-Infrared & 4 & $0.77-0.89$ \\
\hline Pan. & 5 & $0.51-0.73$ \\
\hline
\end{tabular}

Table 2. Pre-launching spatial resolution estimation (CBERS-1): across-tack direction.

(SOURCE: Fonseca et al., 2002).

\begin{tabular}{c|c}
\hline Band & EIFOV $(\mathrm{m})$ \\
\hline $\mathrm{B}_{2}$ & 33.1 \\
\hline $\mathrm{B}_{3}$ & 35.3 \\
\hline $\mathrm{B}_{4}$ & 68.2 \\
\hline
\end{tabular}

Table 4. Black target: estimated parameters for CBERS-1.

\begin{tabular}{c|c|c}
\hline Band & $\begin{array}{c}\text { EIFOV }(\mathrm{m}) \\
\text { along-track } \\
\text { direction }\end{array}$ & $\begin{array}{c}\text { EIFOV }(\mathrm{m}) \\
\text { across-track } \\
\text { direction }\end{array}$ \\
\hline $\mathrm{B}_{2}$ & 34 & 68 \\
\hline $\mathrm{B}_{3}$ & 32 & 68 \\
\hline $\mathrm{B}_{4}$ & 51 & 76 \\
\hline
\end{tabular}

Table 3: Pre-launching spatial resolution estimation (CBERS-2): across- track direction.

(SOURCE: Fonseca et al., 2004).

\begin{tabular}{c|c}
\hline Band & EIFOV $(\mathrm{m})$ \\
\hline $\mathrm{B}_{2}$ & 31.0 \\
\hline $\mathrm{B}_{3}$ & 31.0 \\
\hline $\mathrm{B}_{4}$ & 53.0 \\
\hline
\end{tabular}

Table 5. Black target: estimated parameters for CBERS-2.

\begin{tabular}{c|c|c}
\hline Band & $\begin{array}{c}\text { EIFOV }(\mathrm{m}) \\
\text { along-track } \\
\text { direction }\end{array}$ & $\begin{array}{c}\text { EIFOV }(\mathrm{m}) \\
\text { across-track } \\
\text { direction }\end{array}$ \\
\hline $\mathrm{B}_{2}$ & 32 & 56 \\
\hline $\mathrm{B}_{3}$ & 43 & 54 \\
\hline $\mathrm{B}_{4}$ & 31 & 66 \\
\hline
\end{tabular}


Table 6. Bridge target: estimated EIFOV for CBERS-1.

\begin{tabular}{c|c|c}
\hline Band & $\begin{array}{c}\text { EIFOV }(\mathrm{m}) \\
\text { along-track } \\
\text { direction }\end{array}$ & $\begin{array}{c}\text { EIFOV }(\mathrm{m}) \\
\text { across-track } \\
\text { direction }\end{array}$ \\
\hline $\mathrm{B}_{2}$ & 37 & 67 \\
\hline $\mathrm{B}_{3}$ & 40 & 67 \\
\hline $\mathrm{B}_{4}$ & 64 & 81 \\
\hline
\end{tabular}

Table 7. Bridge target: Estimated EIFOV

for CBERS-2.

\begin{tabular}{c|c|c}
\hline Band & $\begin{array}{c}\text { EIFOV }(\mathrm{m}) \\
\text { along-track } \\
\text { direction }\end{array}$ & $\begin{array}{c}\text { EIFOV }(\mathrm{m}) \\
\text { across-track } \\
\text { direction }\end{array}$ \\
\hline $\mathrm{B}_{2}$ & 39 & 62 \\
\hline $\mathrm{B}_{3}$ & 47 & 62 \\
\hline $\mathrm{B}_{4}$ & 45 & 61 \\
\hline
\end{tabular}

Table 8: SPOT-4 EIFOV

(Fonseca, 2004).

\begin{tabular}{c|c|c}
\hline Band & $\begin{array}{l}\text { EIFOV }(\mathrm{m}) \\
\text { along-track } \\
\text { direction }\end{array}$ & $\begin{array}{l}\text { EIFOV }(\mathrm{m}) \\
\text { across-track } \\
\text { direction }\end{array}$ \\
\hline $\mathrm{B}_{2}$ & 28 & 27 \\
\hline $\mathrm{B}_{3}$ & 30 & 29 \\
\hline $\mathrm{B}_{4}$ & 31 & 34 \\
\hline
\end{tabular}

Table 9: Estimated EIFOV

for CBERS-1.

\begin{tabular}{c|c|c}
\hline Band & $\begin{array}{c}\text { EIFOV }(\mathrm{m}) \\
\text { along-track } \\
\text { direction }\end{array}$ & $\begin{array}{c}\text { EIFOV }(\mathrm{m}) \\
\text { across-track } \\
\text { direction }\end{array}$ \\
\hline $\mathrm{B}_{2}$ & 34 & 65 \\
\hline $\mathrm{B}_{3}$ & 37 & 64 \\
\hline $\mathrm{B}_{4}$ & 54 & 77 \\
\hline
\end{tabular}

Table 10: Estimated EIFOV

for CBERS-2.

\begin{tabular}{c|c|c}
\hline Band & $\begin{array}{c}\text { EIFOV }(\mathrm{m}) \\
\text { along-track } \\
\text { direction }\end{array}$ & $\begin{array}{c}\text { EIFOV }(\mathrm{m}) \\
\text { across-track } \\
\text { direction }\end{array}$ \\
\hline $\mathrm{B}_{2}$ & 34 & 59 \\
\hline $\mathrm{B}_{3}$ & 39 & 59 \\
\hline $\mathrm{B}_{4}$ & 36 & 63 \\
\hline
\end{tabular}


Table 11: Mean EIFOV for CBERS-2

obtained by

(J. Jun Sun, personal communication, 2004)

\begin{tabular}{c|c|c}
\hline Band & $\begin{array}{c}\text { EIFOV }(\mathrm{m}) \\
\text { along-track } \\
\text { direction }\end{array}$ & $\begin{array}{c}\text { EIFOV }(\mathrm{m}) \\
\text { across-track } \\
\text { direction }\end{array}$ \\
\hline $\mathrm{B}_{2}$ & 34 & 53 \\
\hline $\mathrm{B}_{3}$ & 40 & 53 \\
\hline $\mathrm{B}_{4}$ & 39 & 51 \\
\hline
\end{tabular}

Table 12: Mean EIFOV for CBERS-2

obtained in this work.

\begin{tabular}{c|c|c}
\hline Band & $\begin{array}{c}\text { EIFOV }(\mathrm{m}) \\
\text { along-track } \\
\text { direction }\end{array}$ & $\begin{array}{c}\text { EIFOV }(\mathrm{m}) \\
\text { across-track } \\
\text { direction }\end{array}$ \\
\hline $\mathrm{B}_{2}$ & 35 & 59 \\
\hline $\mathrm{B}_{3}$ & 43 & 58 \\
\hline $\mathrm{B}_{4}$ & 37 & 63 \\
\hline
\end{tabular}

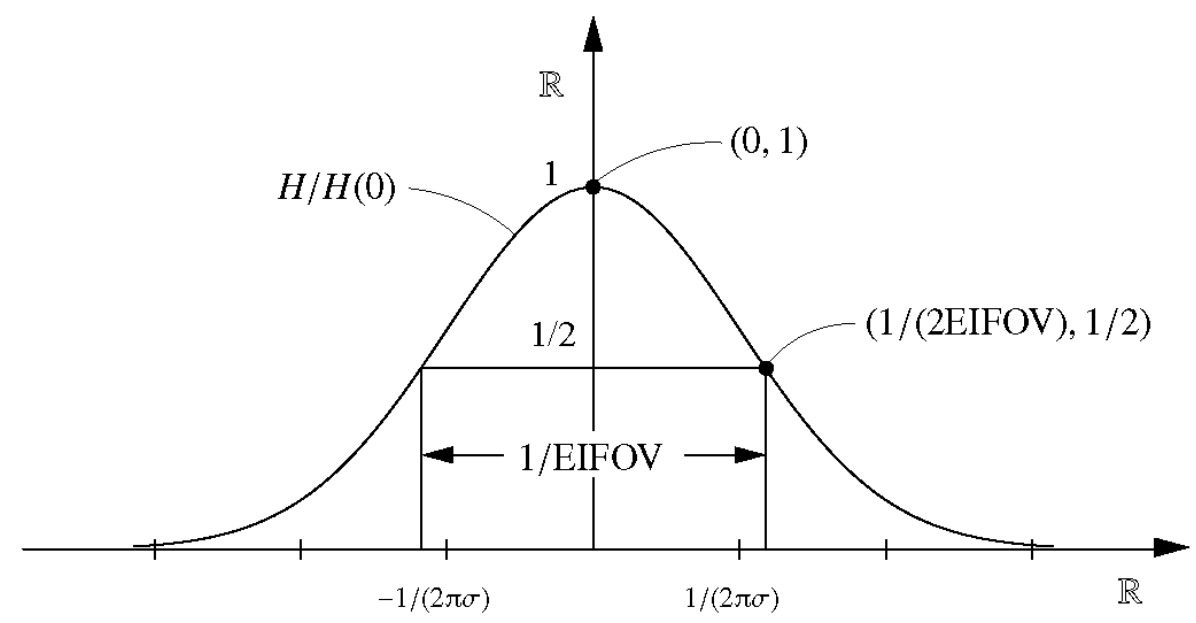

Figure 1. Relation between the EIFOV parameter and the Gaussian MTF graph.

SOURCE: Banon and Santos (1993). 


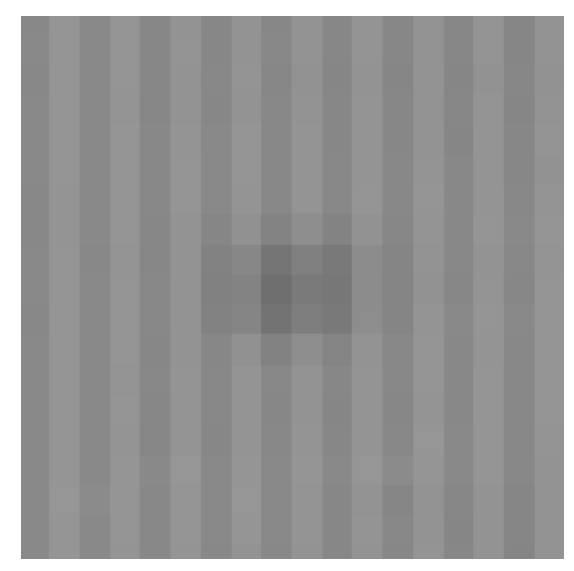

Figure 2. Original target image (band 3).

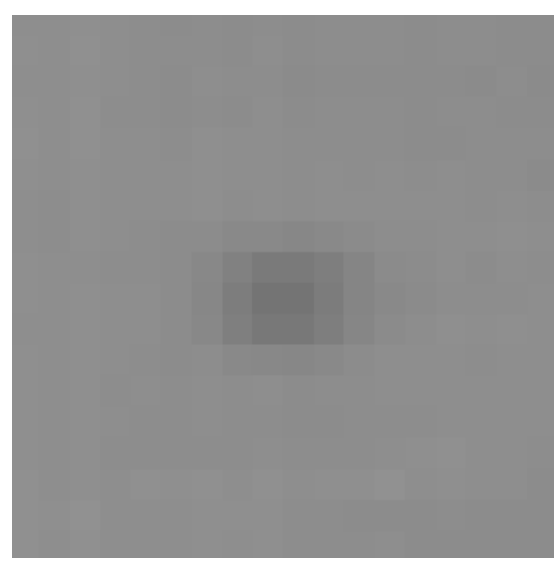

Figure 3: Target image after

destriping (band 3).

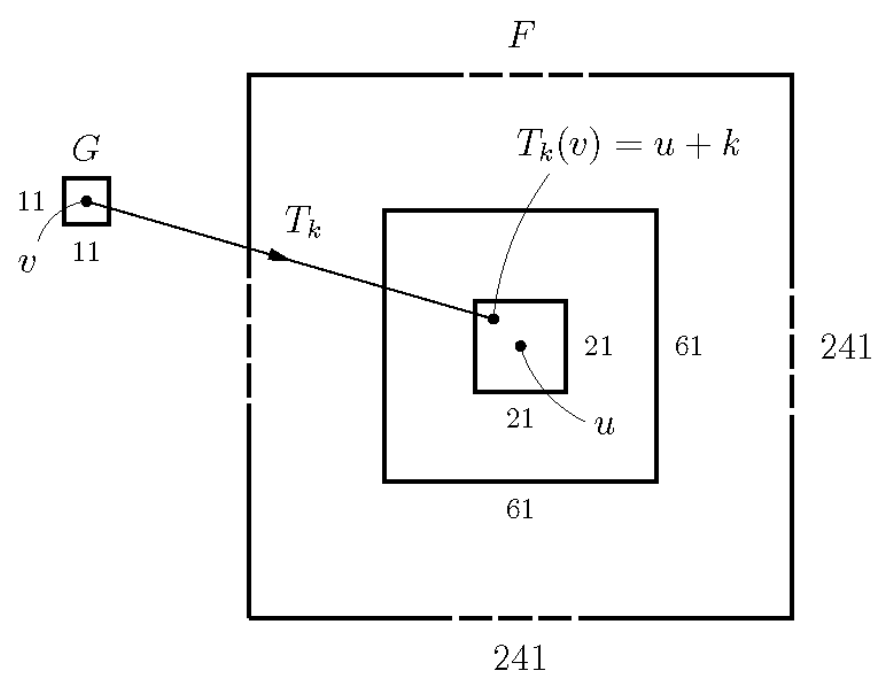

Figure 4: Digital target model (dimensions are in meter). 


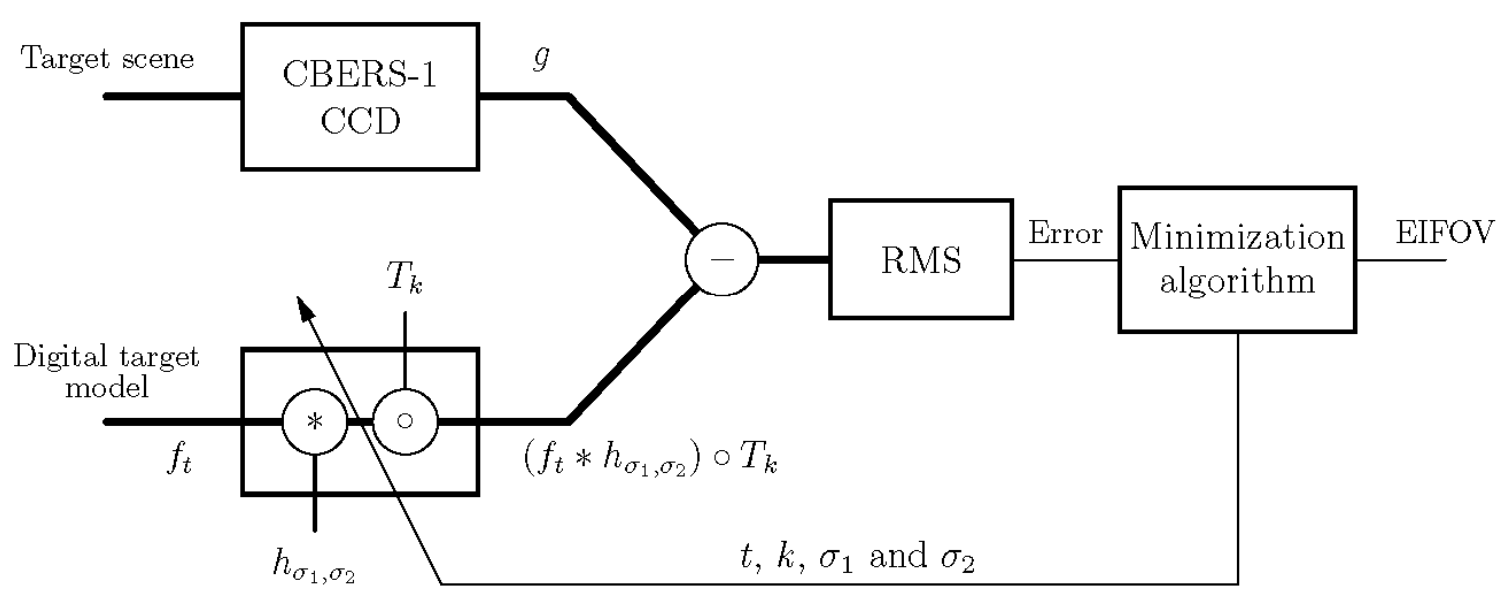

Figure 5: Block diagram of the PSF identification process.

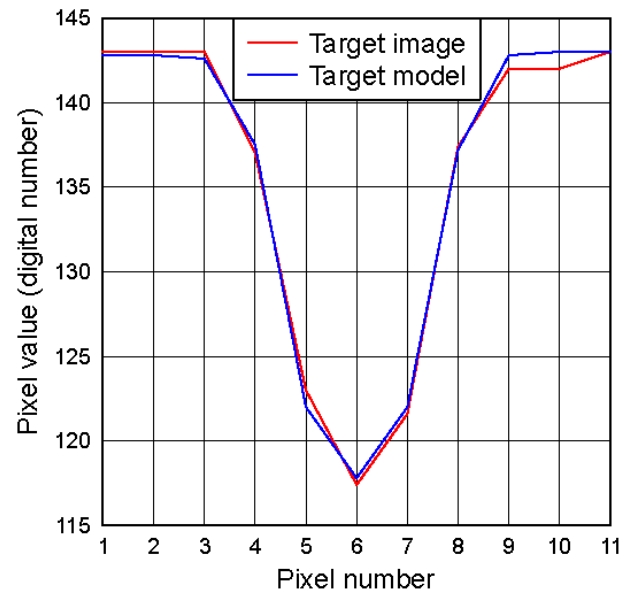

Figure 6: Along-track fitting for band 3 of CBERS-1 (pixel number versus pixel value).

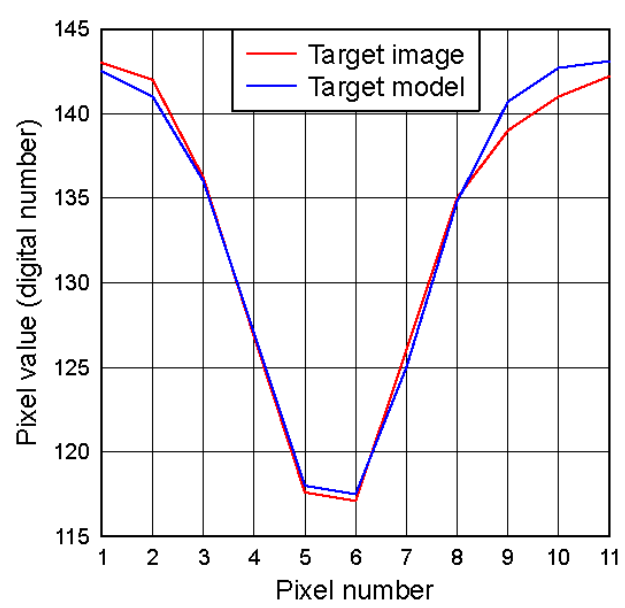

Figure 7: Across-track fitting for band 3 of CBERS-1 (pixel number versus pixel value). 


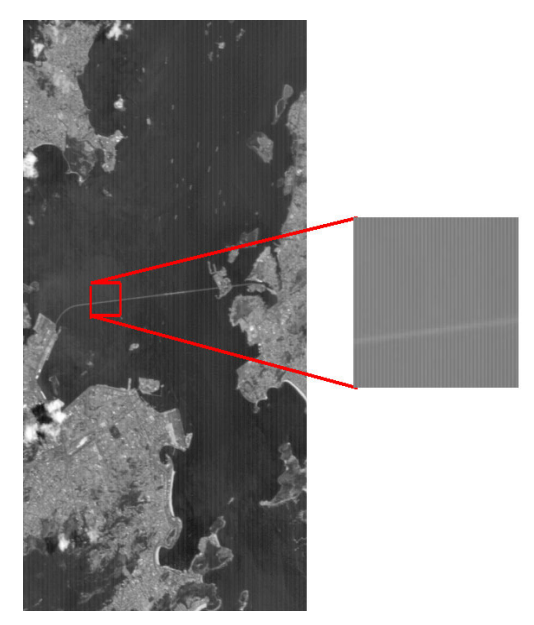

Figure 8: Selected sub-image of Rio-Niterói bridge.

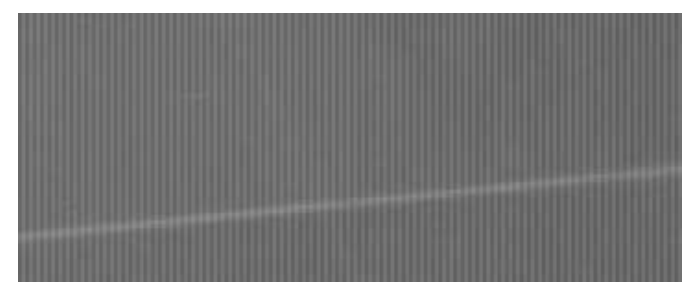

(a)

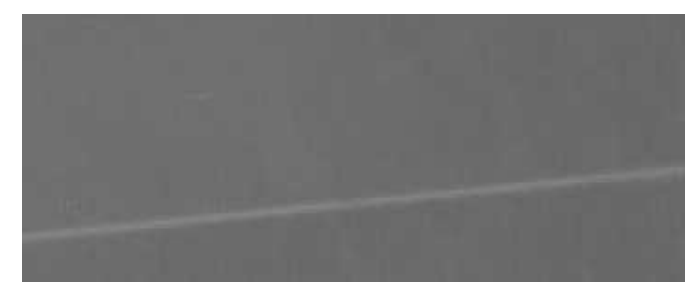

(b)

Figure 10: Original and processed Rio- Niterói Bridge image (band3).

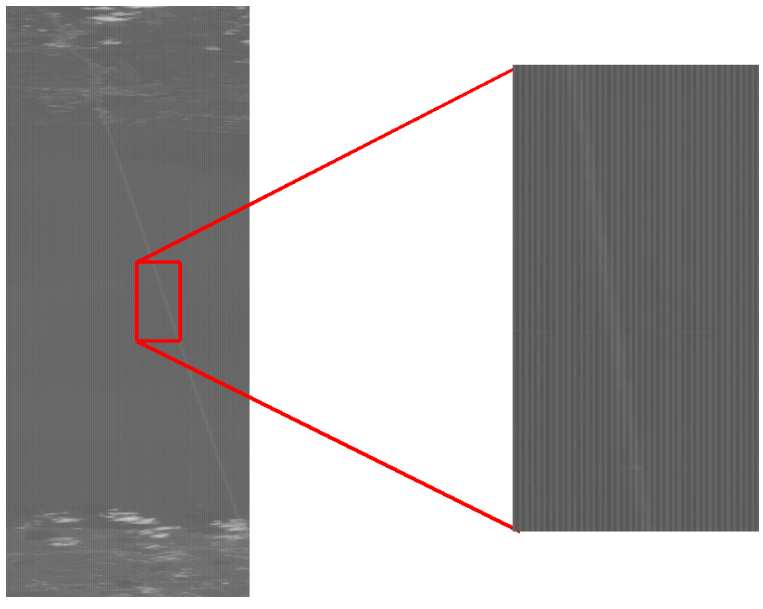

Figure 9: Selected sub-image of Causeway bridge.

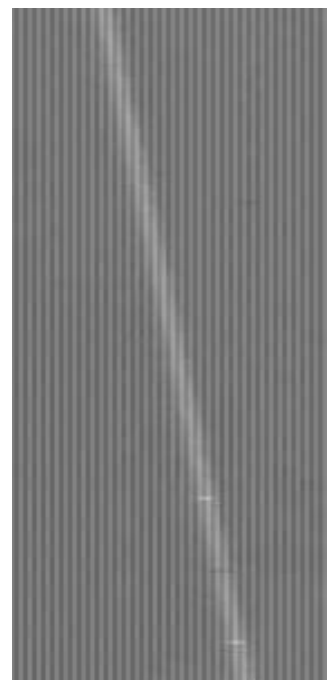

(a)

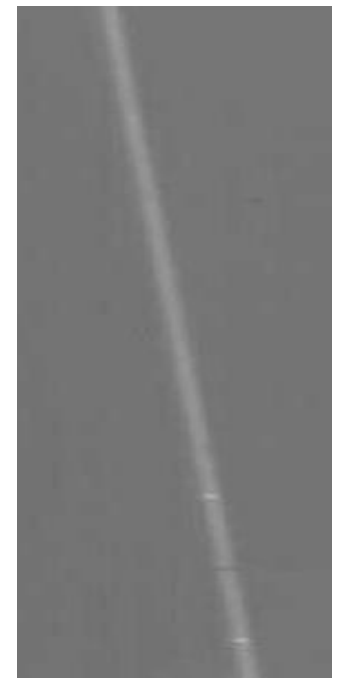

(b)
Figure 11: Original and processed Causeway bridge image (band3). 


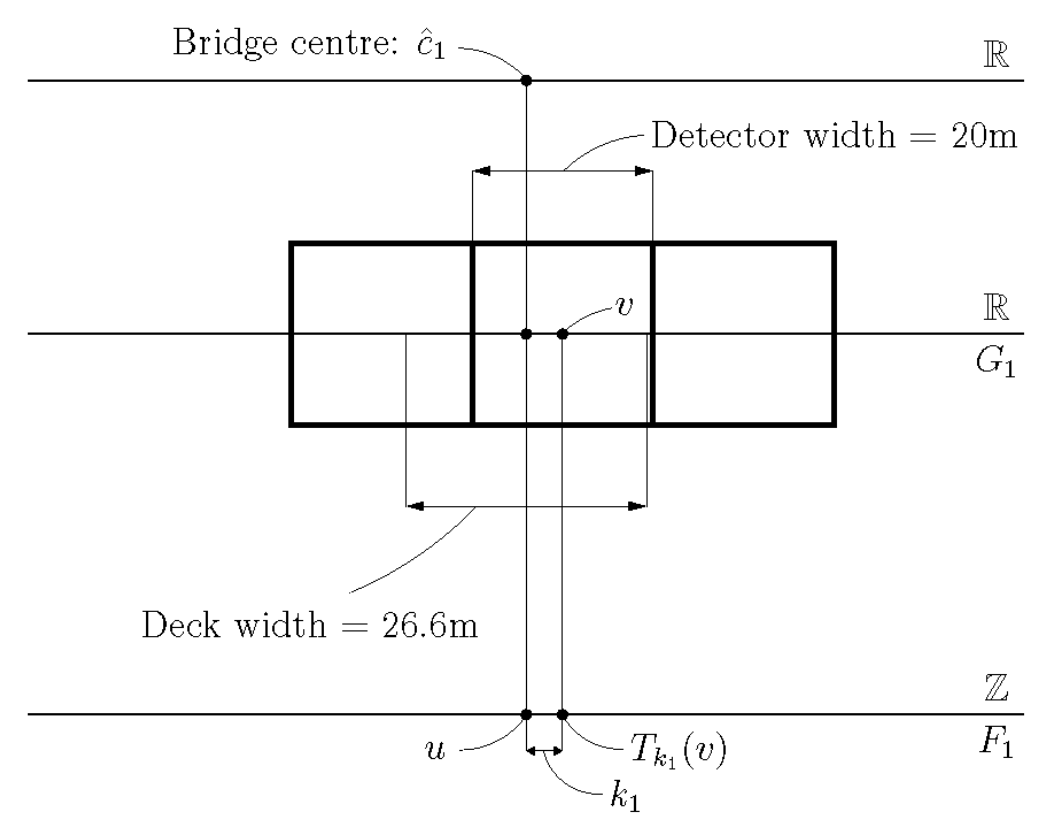

Figure 12: Rio-Niterói bridge model..

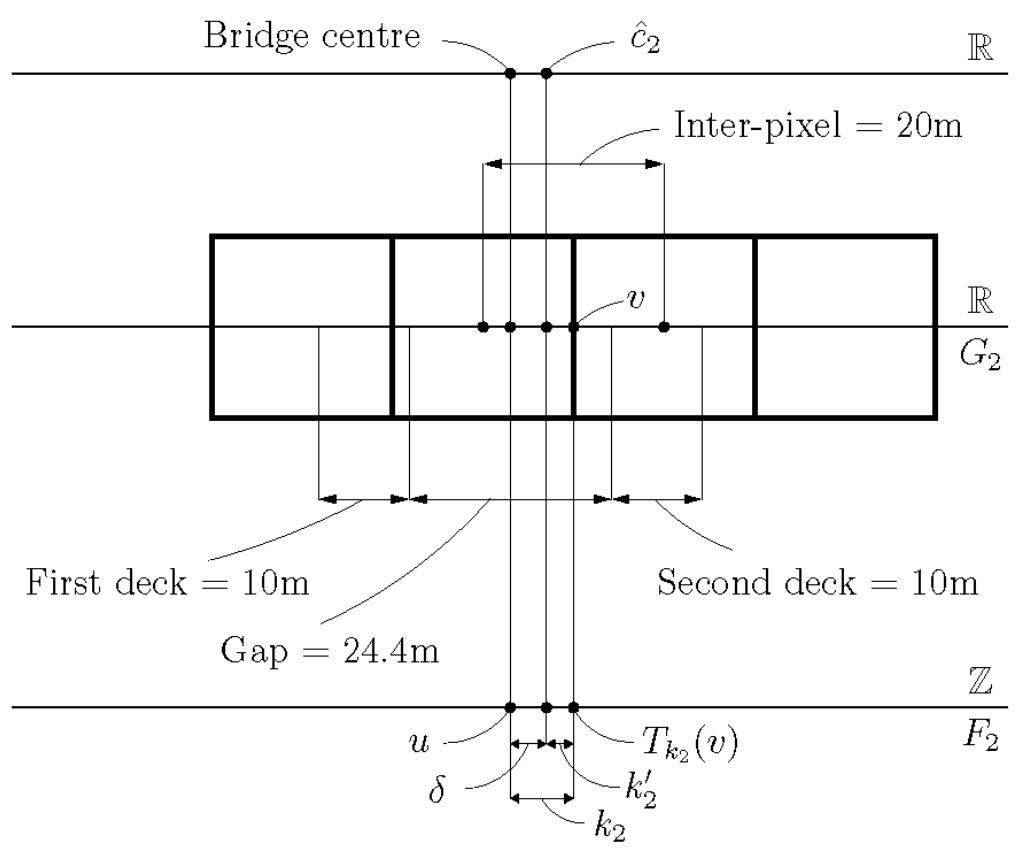

Figure 13: Causeway bridge model. 


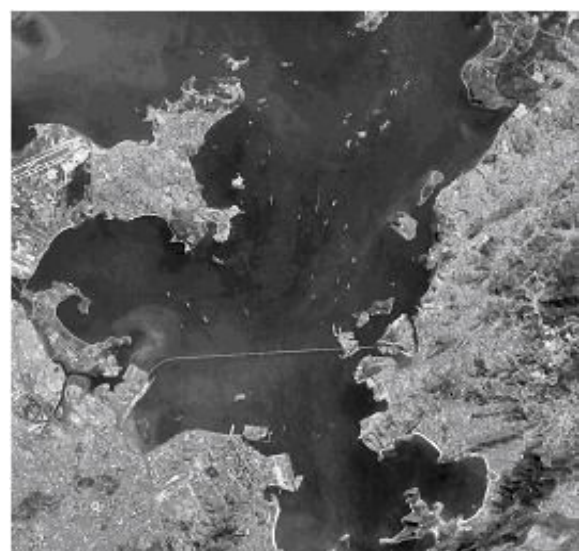

Figure 14: Rio-Niterói bridge

image acquired by SPOT 4 (Band2).

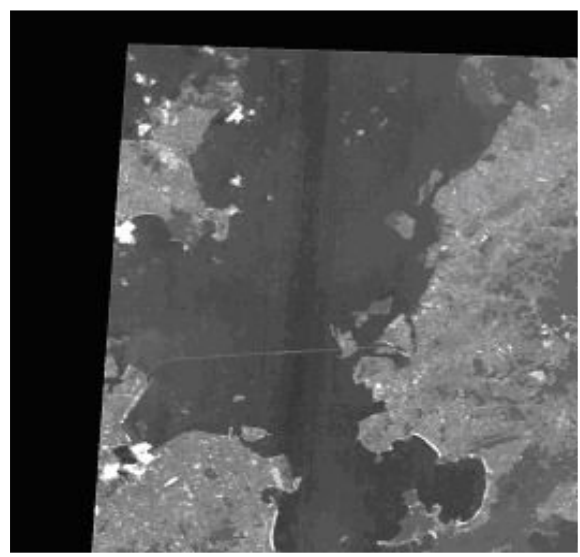

Figure 16: Registered CBERS Image

(Rio-Niterói bridge).

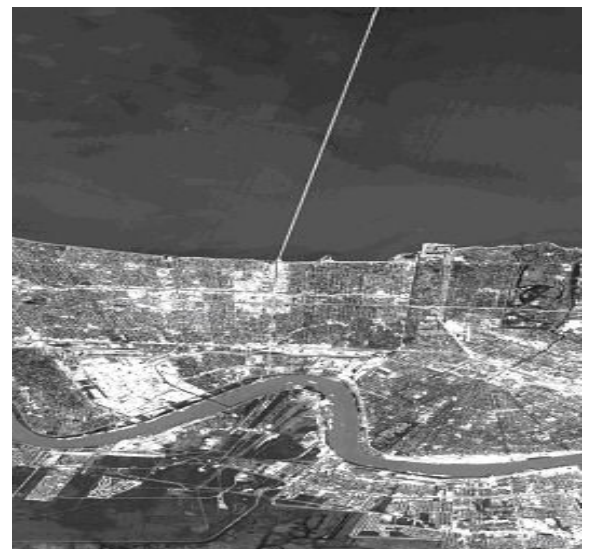

Figure 15: Causeway bridge

image acquired by SPOT 4 (Band2).

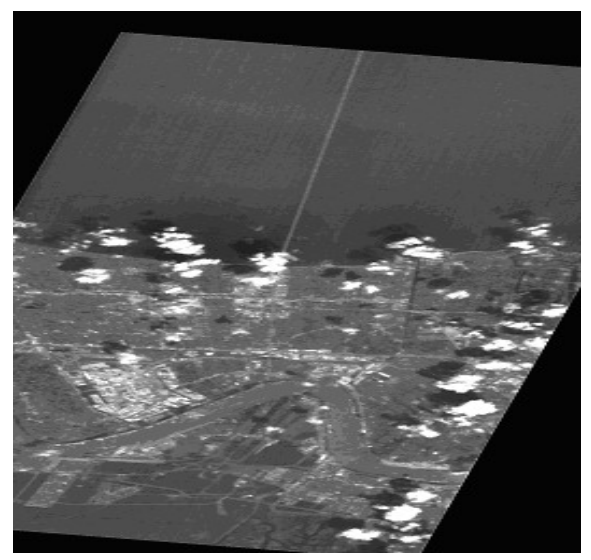

Figure 17: Registered CBERS image

(Causeweay bridge). 


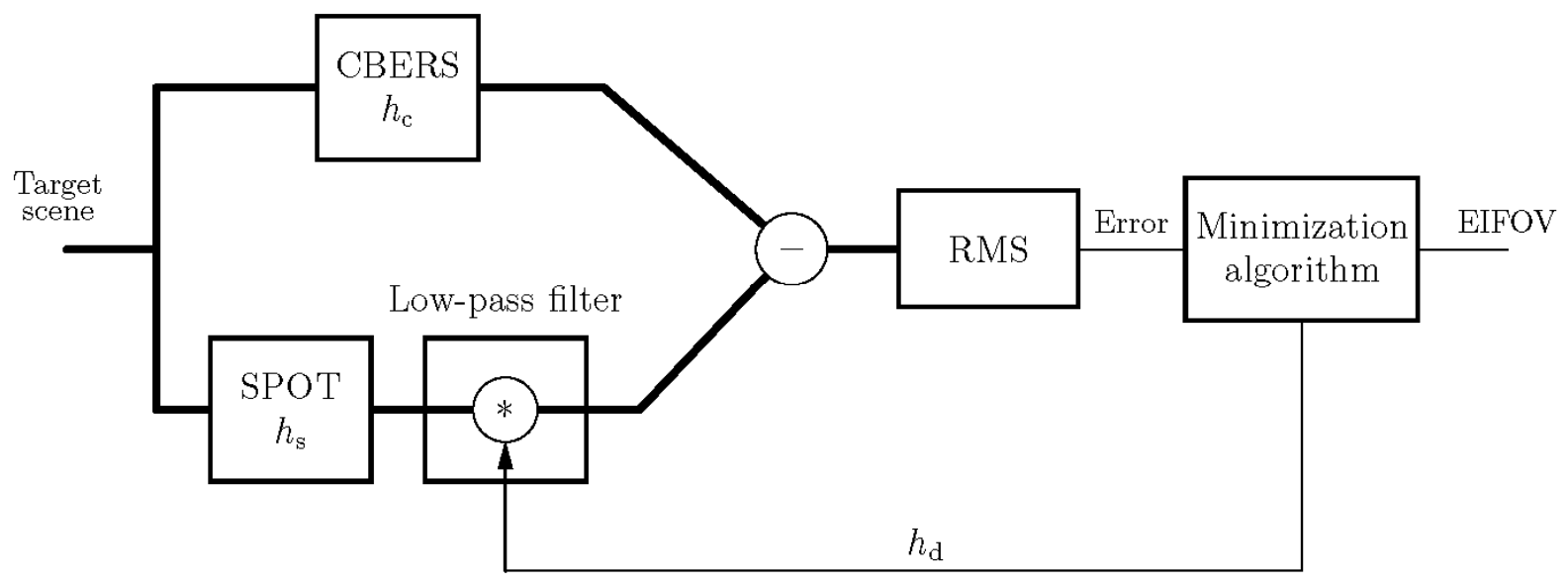

Figure 18: Block diagram of the low-resolution image simulation process. 